\title{
Acoustic Study of Tone 3 Sandhi in Beijing and Taiwan Mandarin
}

\author{
Hui Yin ${ }^{1}$ \\ ${ }^{1}$ Department of English, Xi' an Jiaotong-Liverpool University, Suzhou, China \\ Correspondence: Hui Yin, Department of English, Xi'an Jiaotong-Liverpool University, Suzhou, 215123, China. \\ E-mail: hui.yin@xjtlu.edu.cn
}

Received: November 26, 2019 Accepted: January 3, 2020 Online Published: February 5, 2020

doi:10.5539/ijel.v10n2p98

URL: https://doi.org/10.5539/ijel.v10n2p98

\begin{abstract}
Studies on Mandarin tone sandhi have focused on Beijing Mandarin. Taiwan has been politically separated from mainland China since 1949, but it is not known if tone sandhi in Taiwan Mandarin displays different patterns or characteristics. However, there has been no comparative study to investigate if Beijing Mandarin and Taiwan Mandarin display the same tone sandhi pattern. This study aims to fill this gap by comparing Beijing and Taiwan Mandarin through a productive experiment to examine acoustic differences between sandhied tone 3 and lexical tone 2. The results indicate that tone 3 sandhi among Mandarin dialects is not a homogeneous category, but displays a graded phenomenon of a categorical change and tonal reduction. The experimental evidence shows that acoustic difference between sandhied tone 3 and lexical tone 2 is larger in Beijing Mandarin than that in Taiwan Mandarin. Gender effects are also detected and acoustic difference in female samples is consistently larger than that in male samples across Beijing and Taiwan Mandarin. The findings suggest that the third tone sandhi in Beijing Mandarin is more like a categorical change (i.e., changed to lexical tone 2) whereas the sandhi in Taiwan Mandarin is more like a tonal reduction.
\end{abstract}

Keywords: tone sandhi, acoustic difference, Beijing, Taiwan Mandarin

\section{Introduction}

There are four basic tones in Mandarin and every stressed syllable belongs to one of the four, although actual realizations may vary according to context. When the four tones are applied to the same syllable, four different lexical items result (Wang \& Norval, 1997). A classic example of tonal contrasts is illustrated in (1):

\begin{tabular}{|c|c|c|c|}
\hline syllable & tone & Numbers to represent & gloss \\
\hline $\mathrm{ma}$ & tone 1 (high level) & 55 & 'mother' \\
\hline ma & tone 2 (high rise) & 35 & 'numb' \\
\hline $\mathrm{ma}$ & tone 3 (fall-rise) & 214 & 'horse' \\
\hline ma & tone 4 (falling) & 51 & 'curse' \\
\hline
\end{tabular}

In analyzing the Mandarin tonal system, the voice range is divided into five levels. The numbers from 1 to 5 are used to designate these levels, where 1 represents the lowest comfortable pitch of the voice range and 5 represents the highest. The first tone (tone 1) (55) is high and level. It is pitched near the top of the comfortable voice range. The second tone (tone 2) (35) starts around the middle of the voice range 3 and rises straight towards the level of the first tone 5. The third tone (tone 3) (214) begins near the bottom of the comfortable voice range 2 , proceeds to the bottom 1 , and then upward to end above the middle range 4 . The fourth tone (tone 4) (51) begins at the top of the comfortable voice range 5 and falls quickly to the bottom range 1 (Chao, 1930, 1968).

A well-known phenomenon in Mandarin phonology is tonal modifications according to different contexts, among which tone 3 sandhi is the most noticeable (Yin, 2003, p. 296). In traditional analyses, the basic rule of Mandarin tone 3 sandhi can be stated as in (2):

(2) $3 \rightarrow>[2] / \_3$

When one tone 3 syllable is immediately followed by another, the first of the two changes from a "falling-rising tone [214] into high rising [35]" (Chen, 2000, p. 20) i.e., tone 2. For example, in the case of hao3 ma3 'good horse' as in (3) the tone of the first syllable in this disyllabic compound will be changed from tone 3 to tone 2 . 
(Throughout the paper, a number immediately following a syllable is used to represent a particular tone.)

$\begin{array}{ll}\text { (3) hao3 } & \text { ma3 } \rightarrow \text { hao [2] ma3 } \\ \text { 好 } & \text { 马 } \\ \text { good } & \text { horse }\end{array}$

When tone 3 sandhi applies to a linguistic expression more than two syllables, the rule in (3) should be changed to that in (4).

(4) $3 \rightarrow>[2] /[3 n$

In (4), ' $n$ ' indicates that the sandhi rule is in fact a schema expandable to include a string of consecutive third tones as in (5).

\begin{tabular}{|c|c|c|c|}
\hline ) a. & mai3 & hao3 & $\mathrm{ma} 3 \rightarrow$ mai [2] hao [2] ma3 \\
\hline & 买 & 好 & 马 \\
\hline & buy & good & horse \\
\hline b. & mai3 & hao3 & $\mathrm{ma} 3 \rightarrow$ mai [3] hao [2] ma3 \\
\hline & 买 & 好 & 马 \\
\hline & buy & good & horse \\
\hline
\end{tabular}

In (5a), there are three tone 3 syllables in succession, and all the third tones except for the last one are changed into the second tones by tone 3 sandhi rule. But (5b) indicates that between the boundary of a verb and its object, the application of the sandhi rule can be optional.

In a compound or phrase larger than two syllables or a sentence, since the sandhi rule application largely depends on speech rates, syntactic boundaries and pragmatic factors, the rule can be applied optionally in many cases (Yin, 2003, p. 301). However, in a disyllabic compound or phrase the rule should apply obligatorily; therefore, compounds or phrases with two syllables are a good choice to test tone sandhi in Mandarin. Thus, the stimuli for the present study were all disyllabic compounds or phrases where the first of the two tones must undergo the sandhi.

In Mandarin tone 3 sandhi literature, there are two different views: one treats tone 3 sandhi as a categorical change while the other deems it a phenomenon of tonal reduction. Wang and Li's perceptual experiment results suggest that Mandarin speakers have difficulty in distinguishing sandhied tone 3 and lexical tone 2 (1967). Chen (2000, p. 20) claims that the sandhi rule turns a falling-rising tone [214] into a high-rising one [35], that is, sandhied tone 3 is fully neutralized to lexical tone 2. However, Lin (2001, pp. 47-48) proposes that a full tone 3 contains three tonemes and she maintains that tone 3 in a non-final syllable is shortened so that it loses the last toneme in connected speech. Yin (2003) proposes an OT analysis and claims that sandhied tone 3 keeps its rising portion (the second half) and loses its falling portion (the first half). Yuan and Chen (2014) treat tone 3 sandhi as a tonal reduction as well by claiming that sandhied tone 3 is changed from 214 to 24 , that is, it takes a shortcut to reach its final destination by starting from initial point 2 and goes straightforward to the end point 4 .

Although the debate on whether the third tone sandhi phenomenon involves a categorical change or tonal reduction has started over half century ago, it is still going on and the issue has yet to be resolved. In the past, research on Mandarin tone sandhi has focused on Beijing Mandarin and tone sandhi of other Mandarin dialects has been largely ignored. Taiwan has been politically separated from mainland China since 1949 and tone sandhi in Taiwan Mandarin may display different patterns or characteristics. However, few studies have been conducted to investigate tone sandhi in Taiwan Mandarin. Moreover, there has been no study to compare tone 3 sandhi between Beijing Mandarin and Taiwan Mandarin (James \& Tsai, 2003; Yin, 2017). This research is sought to fill this gap. The present study focuses on tone 3 sandhi which is the most complicated tonal change in Mandarin (Yin, 2003). Instead of focusing on one representative Mandarin dialect such as Beijing Mandarin, this study aims to compare acoustic differences between sandhied tone 3 and lexical tone 2 between Beijing and Taiwan Mandarin and expects to shed light on the nature of tone 3 sandhi in Mandarin.

\section{Method}

The study is sought to investigate acoustic differences between sandhied tone 3 and lexical tone 2 between Beijing and Taiwan Mandarin to find out if they display the same or different tone 3 sandhi pattern. To achieve this aim, an experiment was conducted and Beijing and Taiwan Mandarin speakers were invited to produce Mandarin words or phrases with two syllables. In order to conduct a comparative study, in this experiment the 
same method (including the same stimuli, same procedure and same measurement) was used for the two Mandarin dialects.

\subsection{Participants}

The participants for the experiment were 40 Beijing Mandarin speakers and 40 Taiwan Mandarin speakers. Beijing Mandarin speakers were born and raised in Beijing and they were recruited from Beijing and Xi'an Jiaotong-Liverpool University, an international Sino-British cooperative university located in Suzhou, China. Taiwan Mandarin speakers were born and raised in Taiwan and they were recruited from Taipei, Taiwan and Xi'an Jiaotong-Liverpool University. Among the 40 Beijing and Mandarin speakers, half of them were males and another half were females so genders for this experiment were balanced. In this study, gender effects in acoustic differences between sandhied tone 3 and lexical tone 2 were also investigated. All of the participants for this experiment were remunerated for their participation in this study.

\subsection{Stimuli}

The stimuli for the experiment were 15 pairs of disyllabic compounds or phrases with tone 3 on the second syllable and tone 2 or tone 3 on the first as (6) and (7) illustrate.
(6) (a) zu (tone 3) zhang (tone 3) 组长 'group leader'
(b) zu (tone 2) zhang (tone 3) 族长 'clan leader'
(a) mai (tone 3) ma (tone 3) 买马 'buy horses'
(b) mai (tone 2) ma (tone 3) 埋马 'bury horses'

The pair in (6) and (7) are bi-syllabic nominal compounds and verb phrases respectively. However, most of the stimuli for this experiment were nominal compounds. The stimulus in (a) of each pair is a bi-syllabic word or phrase with tone 3 on both the first and the second syllable while that in (b) of each pair is also bi-syllabic with tone 2 on the first syllable and tone 3 on the second. Orthographically, the second characters in each pair are the same. For example, in (6) the second character in (a) is the same as that in (b), that is, zhang (tone 3) 长 'leader'. So, in this experiment the second characters in each pair are held constant by using the same character. In the two stimuli of each pair, actually the first syllables orthographically in Pinyin are also the same except for the tones. For example, the first syllables in Pinyin in both (6a) and (6b) are $z u$, but the tone assigned to the first syllable in (6a) is tone 3 while the tone assigned to its counterpart in (6b) is tone 2 . In this experiment, everything in the stimuli of each pair is held constant except for the tones in the first syllables. Therefore, any acoustic differences between the first syllables in each pair should result from differences between sandhied tone 3 and lexical tone 2 .

\subsection{Procedures}

The 15 pairs of stimuli were presented through PowerPoint slides and for clarity each slide contained only one stimulus. The simplified Chinese characters were presented to the participants of Beijing Mandarin speakers while the traditional Chinese characters were presented to those of Taiwan Mandarin speakers. The slides were set to show automatically at 7 second intervals. Each stimulus was presented on the computer screen for 3 seconds and then participants saw an asterisk $(*)$. In order to control speaking rates, participants were asked to read the stimuli in isolation in their normal speech. In order to avoid reading a stimulus (a bi-morphemic compound or phrase) in a hurry, they were instructed to read the stimulus after they saw an asterisk. The asterisk appeared on the screen for 4 seconds before the next stimulus was presented. Prior to the real stimuli, there was a demonstration session which gave participants hands-on experience in dealing with the actual experiment session. The stimuli were randomized before putting on the PowerPoint slides and participants' readings were recorded. The sampling frequency used for recording participants' speech was $44100 \mathrm{~Hz}$.

\subsection{Measurement}

After the recordings were collected, Audacity — a free multi-track audio editor and recorder was used to edit the stimuli. For convenience of analysis, the stimuli were edited into contrastive pairs with tone $3+$ tone 3 sequences vs. tone $2+$ tone 3 sequences in order to facilitate measuring acoustic differences between sandhied tone 3 and lexical tone 2. When the stimuli were edited, all the recordings were inserted into Praat - a free computer program for the acoustic analysis of speech (Boersma \& Weenink, 2018) to measure fundamental frequency $\left(\mathrm{F}_{0}\right)$ of sandhied tone 3 and lexical tone 2 in the stimuli. In the Praat program, the pitch track function was used to measusre $\mathrm{F}_{0}$ values at different sampling points of the pitch associated with a particular tone. The pitch track function was performed to obtain the minimal and the maximal $\mathrm{F}_{0}$ values, which were used to calculate 'range' in this study. 
Mandarin Chinese is a tone language and every Mandarin syllable has an essential component, that is, a tone, which is primarily the pitch pattern of the voiced part of the syllable (Chao, 1968). Mandarin has four lexical tones which display different patterns of pitch. Pitch can be measured by fundamental frequency $\left(\mathrm{F}_{0}\right)$. One measurement to observe differences between sandhied tone 3 and lexical tone 2 is to compare ranges in $\mathrm{F}_{0}$ between them. Figure 1 is an example to illustrate ranges in $\mathrm{F}_{0}$ between sandhied tone 3 and lexical tone 2 .

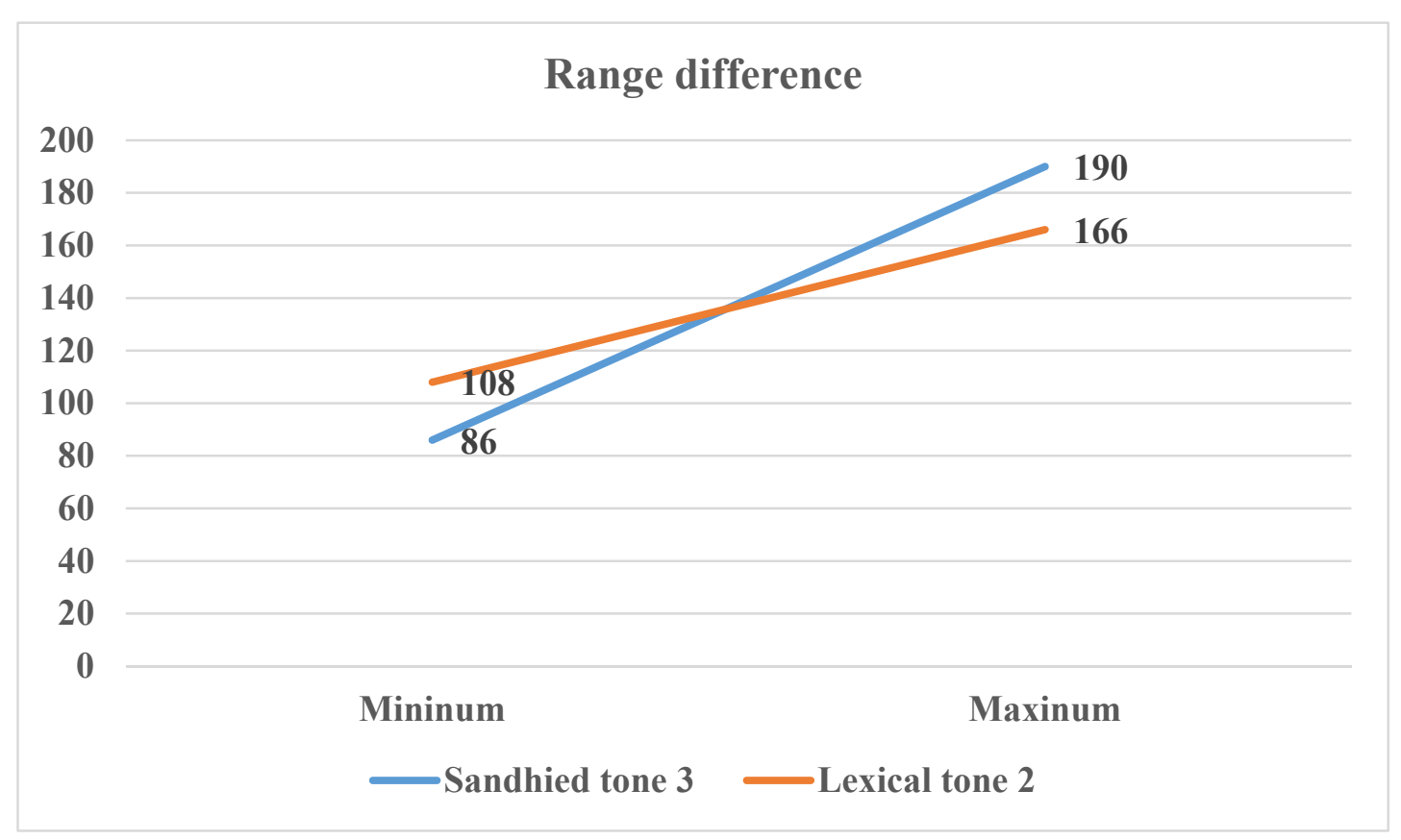

Figure 1. $\mathrm{F}_{0}$ range difference between sandhied tone 3 and lexical tone 2

Figure 1 indicates the lowest point, that is, the minimal $F_{0}$ value and the highest point, that is, the maximal $F_{0}$ value. The two points determine the $\mathrm{F}_{0}$ range for sandhied tone 3 and lexical tone 2 respectively. Table 1 shows measurement of range difference in $\mathrm{F}_{0}$ between sandhied tone 3 and lexical tone 2 .

Table 1. Measurement of range and range difference in $\mathrm{F}_{0}$

\begin{tabular}{llllc}
\hline & Minimal $\mathrm{F}_{0}$ & Maximal $\mathrm{F}_{0}$ & Range & Range difference in $\mathrm{F}_{0}$ \\
\hline Sandhied tone 3 & 86 & 190 & $190-86=104$ & \\
$\begin{array}{l}\text { Lexical tone 2 } \\
\text { Between sandhied tone 3 and lexical tone 2 }\end{array}$ & 108 & 166 & $166-108=58$ & \\
\hline
\end{tabular}

Table 1 shows that 'range' is the difference between the maximal value and the minimal value. Range difference here refers to the difference in $\mathrm{F}_{0}$ between the range of sandhied tone 3 and that of lexical tone 2 . The range difference in $\mathrm{F}_{0}$ in this example is $46 \mathrm{~Hz}$, which can be viewed as a measurement of acoustic difference between sandhied tone 3 and lexical tone 2 . In this study $\mathrm{F}_{0}$ range difference in $\mathrm{Hz}$ was adopted to measure the degree of magnitude of acoustic difference between sandhied tone 3 and lexical tone 2 .

\section{Results and Discussions}

This section will present findings in this study. First, the results of Beijing and Taiwan Mandarin will be presented, and then, range difference in $\mathrm{F}_{0}$ for Beijing and Taiwan Mandarin will be compared.

\subsection{Range Difference in Beijing Mandarin}

Acoustic difference between sandhied tone 3 and lexical tone 2 was measured in Hz. Table 2 shows the percentage of range difference (D) in four different scopes. The four scopes of range difference in $F_{0}$ are as follows: Scope 1: equal or less than $5 \mathrm{~Hz}$ (i.e. between 0 to $5 \mathrm{~Hz}$ ); Scope 2: more than 5 and less than $15 \mathrm{~Hz}$; Scope 3: equal or more than 15 but less than $25 \mathrm{~Hz}$; Scope 4: equal or more than $25 \mathrm{~Hz}$. 
Table 2. Range difference between sandhied tone 3 and lexical tone 2 in Beijing Mandarin

\begin{tabular}{ll}
\hline Scopes & Percent \\
\hline $\mathrm{D}<$ or $=5$ & 31.22 \\
$5<\mathrm{D}<15$ & 37.95 \\
$15<$ or $=\mathrm{D}<25$ & 16.43 \\
$\mathrm{D}=$ or $>25$ & 16.40 \\
\hline
\end{tabular}

Table 2 indicates that for around 31 percent of the stimuli, range difference between sandhied tone 3 and lexical tone 2 is equal or less than $5 \mathrm{~Hz}$. The scope between 5 to $15 \mathrm{~Hz}$ was populated with more cases than any other scope. The table also shows that for nearly one third of the samples, range difference in $F_{0}$ is equal or larger than $15 \mathrm{~Hz}$, which can be considered as large magnitude of range difference.

Next, gender effects in range difference will be investigated. Table 3 shows difference in $\mathrm{F}_{0}$ between sandhied tone 3 and lexical tone 2 for male and female samples.

Table 3. Range difference between sandhied tone 3 and lexical tone 2 for male and female samples in Beijing Mandarin

\begin{tabular}{lll}
\hline Scopes & Percent & \\
\hline & Male & Female \\
$\mathrm{D}<$ or $=5$ & 33.15 & 29.29 \\
$5<\mathrm{D}<15$ & 38.91 & 36.99 \\
$15<$ or $=\mathrm{D}<25$ & 16.74 & 16.12 \\
$\mathrm{D}=$ or $>25$ & 11.20 & 17.60 \\
\hline
\end{tabular}

It can be observed from Table 3 that for 72.06 percent of the male samples, range difference in $\mathrm{F}_{0}$ is less than 15 $\mathrm{Hz}$ while range difference in 66.28 percent of the female samples is less than $15 \mathrm{~Hz}$. The table also indicates that for 27.94 percent of the male samples, range difference is equal or large than $15 \mathrm{~Hz}$, while range difference in 33.72 percent of female samples is equal or large than $15 \mathrm{~Hz}$, which means that nearly 6 percent more female samples have difference in $\mathrm{F}_{0}$ equal or large than $15 \mathrm{~Hz}$ than male samples. It can be seen that the magnitude of range difference in $F_{0}$ between sandhied tone 3 and lexical tone 2 is larger in female samples than in male samples.

In order to examine if the difference is significant, an independent-samples T-test was performed on the means of $\mathrm{F}_{0}$ range differences from male and female samples. Table 4 shows the means and the test result.

Table 4. Means of $F_{0}$ range differences of male and female samples in Beijing Mandarin and the test result

\begin{tabular}{lll}
\hline & Male & Female \\
\hline Mean & 16.55 & 20.86 \\
P-value & 0.024 & \\
\hline
\end{tabular}

Table 4 shows that the mean of range difference in $\mathrm{F}_{0}$ from female samples is larger than that from male samples in Beijing Mandarin. The p-value of the T-test indicates that the acoustic difference between male and female samples in Beijing Mandarin is significant.

\subsection{Range Difference in Taiwan Mandarin}

Taiwan Mandarin is a prominent Mandarin dialect which is called Guoyu 国语 'national language' and used as the official language in Taiwan. Table 5 shows the percentage of range difference in $\mathrm{Hz}$ in four different scopes.

Table 5. Range difference between sandhied tone 3 and lexical tone 2 in Taiwan Mandarin

\begin{tabular}{ll}
\hline Scopes & Percent \\
\hline $\mathrm{D}<$ or $=5$ & 41.60 \\
$5<\mathrm{D}<15$ & 34.16 \\
$15<$ or $=\mathrm{D}<25$ & 10.61 \\
$\mathrm{D}=$ or $>25$ & 13.63 \\
\hline
\end{tabular}


Table 5 indicates that for 41.6 percent of the stimuli, range difference between sandhied tone 3 and lexical tone 2 is equal or less than $5 \mathrm{~Hz}$. Different from the situation in Beijing Mandarin, for Taiwan Mandarin, the scope of being equal or less than $5 \mathrm{~Hz}$ covers more of the cases than any other scope. The table also shows that for nearly one quarter of the samples, range difference in $\mathrm{F}_{0}$ is equal or larger than $15 \mathrm{~Hz}$. In Taiwan Mandarin, samples in the scope of being equal or larger than $15 \mathrm{~Hz}$ (which is considered as large magnitude of range difference) are less than those in Beijing Mandarin.

Next, gender effects in range difference will be investigated. Table 6 shows range difference in $\mathrm{F}_{0}$ between sandhied tone 3 and lexical tone 2 for male and female samples in Taiwan Mandarin.

Table 6. Range difference between sandhied tone 3 and lexical tone 2 for male and female samples in Taiwan Mandarin

\begin{tabular}{lll}
\hline Ranges & Percent & \\
\hline & Male & Female \\
$\mathrm{D}<$ or $=5$ & 54.56 & 28.65 \\
$5<\mathrm{D}<15$ & 31.73 & 36.60 \\
$15<$ or $=\mathrm{D}<25$ & 8.36 & 12.85 \\
$\mathrm{D}=$ or $>25$ & 5.36 & 21.90 \\
\hline
\end{tabular}

It can be observed from Table 6 that for 86.29 percent of the male samples, range difference in $\mathrm{F}_{0}$ is less than 15 $\mathrm{Hz}$, but for female samples, only 65.25 percent has range difference which is less than $15 \mathrm{~Hz}$. The table also indicates that for only 13.72 percent of the male samples, range difference in $\mathrm{F}_{0}$ is equal or large than $15 \mathrm{~Hz}$, while range difference in 34.75 percent of female samples is equal or large than $15 \mathrm{~Hz}$, which means that 21 percent more female samples have range difference larger than $15 \mathrm{~Hz}$ than male samples. It can be seen from the table that the magnitude of range difference in $\mathrm{F}_{0}$ between sandhied tone 3 and lexical tone 2 is larger in female samples than in male samples.

To examine if the acoustic difference is significant, an independent-samples T-test was performed on $\mathrm{F}_{0}$ range differences from male and female samples. Table 7 shows the means and the test result.

Table 7. Means of $F_{0}$ range differences of male and female samples in Taiwan Mandarin and the test result

\begin{tabular}{lll}
\hline & Male & Female \\
\hline Mean & 8.15 & 20.45 \\
P value & $<0.001$ & \\
\hline
\end{tabular}

Table 7 shows that the mean of range difference in $\mathrm{F}_{0}$ from female samples is larger than that from male samples in Taiwan Mandarin. The p-value of the T-test indicates that the acoustic difference between male and female samples in Taiwan Mandarin is highly significant.

From the tables presented so far, it can be seen that there is acoustic difference in $\mathrm{F}_{0}$ between sandhied tone 3 and lexical tone 2 though the degrees of difference are different between the two dialects-Beijing Mandarin and Taiwan Mandarin. The findings suggest that sandhied tone 3 in both Mandarin dialects is not fully neutralized to lexical tone 2. Gender effects in range difference in $\mathrm{F}_{0}$ between sandhied tone 3 and lexical tone 2 were observed and the magnitude of the difference is larger in female samples than that in male samples across the two Mandarin dialects. The gender effects indicate that the third tone sandhi in female samples is more like a kind of tonal reduction phenomenon than that in male samples. Another factor which possibly causes the gender difference may be differences in $\mathrm{F}_{0}$ between males and females. Generally, females' fundamental frequency $\left(\mathrm{F}_{0}\right)$ is higher than that of males. Hence, higher fundamental frequency of females could be a factor which contributes to larger range difference between sandhied tone 3 and lexical tone 2 in female samples.

\subsection{Comparison of Acoustic Difference in Beijing and Taiwan Mandarin}

This sub-section will compare acoustic range difference between sandhied tone 3 and lexical tone 2 in Beijing and Taiwan Mandarin. Figure 2 shows range difference in $\mathrm{F}_{0}$ in the two prominent Mandarin dialects. 


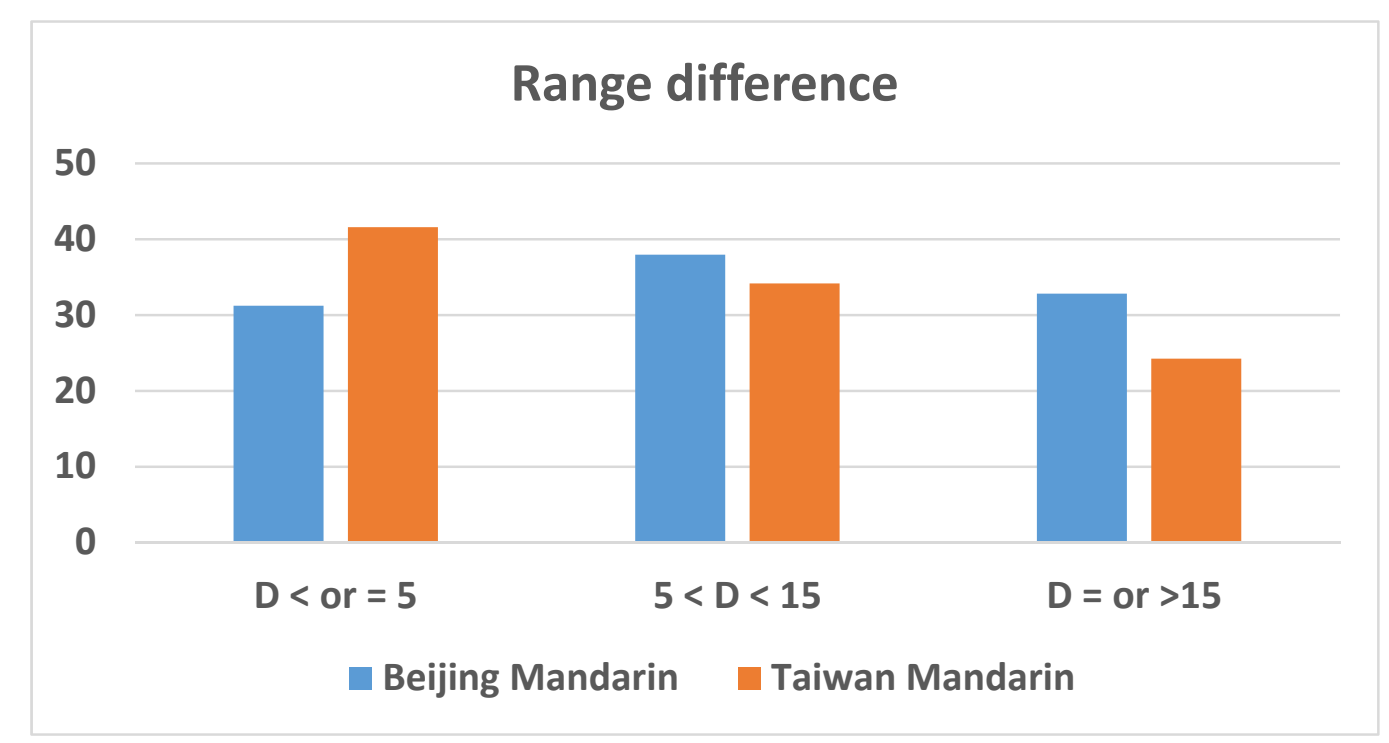

Figure 2. Range difference between sandhied tone 3 and lexical tone 2 in Beijing and Taiwan Mandarin

It can be found from Figure 2 that in terms of range difference Taiwan Mandarin has more cases in the scope of being equal or less than $5 \mathrm{~Hz}$ than Beijing Mandarin. This scope is considered as small magnitude of range difference in $\mathrm{F}_{0}$. Actually, in Taiwan Mandarin more cases fall in this scope than any of the other two scopes in the figure and cases of the third tonal modification with range difference of being equal or less than $5 \mathrm{~Hz}$ are more like a phenomenon of tonal reduction rather than a categorical change to a second tone. Therefore, tone 3 sandhi in Taiwan Mandarin is more like a tonal reduction than that in Beijing Mandarin.

On the other hand, Beijing Mandarin has more cases with range difference equal or more than $15 \mathrm{~Hz}$ than Taiwan Mandarin. This scope is considered as large magnitude of range difference in $\mathrm{F}_{0}$ and cases with range difference falling in this scope are more like a categorical change to a second tone than a phenomenon of tonal reduction. In fact, in Beijing Mandarin the scope of range difference of being equal or more than $15 \mathrm{~Hz}$ covers more cases than the scope with range difference of being equal or less than $5 \mathrm{~Hz}$. Therefore, tone 3 sandhi in Beijing Mandarin is more like a categorical change than that in Taiwan Mandarin.

Also, it can be observed form Figure 2 that cases of range difference between sandhied tone 3 and lexical tone 2 spread in the three scopes across Beijing and Taiwan Mandarin. Although there are more cases in one particular scope than others in either of the two Mandarin dialects, cases of range difference are not heavily concentrated in one particular scope of range difference. Cases of range difference in the scope equal or less than $5 \mathrm{~Hz}$ are more like a tonal reduction phenomenon while those in the scope of equal or more than $15 \mathrm{~Hz}$ are more like a categorical change to tone 2. It is interesting to note that in both Beijing and Taiwan Mandarin, around one-third cases fall in the intermediate scope, that is, larger than $5 \mathrm{~Hz}$ and smaller than $15 \mathrm{~Hz}$. The evidence obtained from this study suggests that like many other linguistic units which are graded phenomena (e.g., Langacker, 1987, 1991, 2008), the third tone sandhi in Mandarin displays a graded phenomenon between a categorical change and tonal reduction. However, tone 3 sandhi in Beijing and Taiwan Mandarin reflects different patterns. Tone 3 sandhi in Beijing Mandarin is closer to a categorical change in this continuum than that in Taiwan Mandarin while tone 3 sandhi in Taiwan Mandarin is closer to a tonal reduction in this spectrum than that in Beijing Mandarin.

In order to examine if the difference between Beijing and Taiwan Mandarin is significant, an independent-samples T-test was conducted on $\mathrm{F}_{0}$ range differences between Beijing and Taiwan Mandarin samples. Table 8 shows the means and the test result.

Table 8. Means of $\mathrm{F}_{0}$ range differences between Beijing and Taiwan Mandarin and the test result

\begin{tabular}{lll}
\hline & Beijing Mandarin & Taiwan Mandarin \\
\hline Mean & 18.71 & 14.30 \\
$P$ value & $<0.001$ & \\
\hline
\end{tabular}


Table 8 shows that the mean of range difference in $\mathrm{F}_{0}$ from Beijing Mandarin is larger than that from Taiwan Mandarin. The p-value of the T-test indicates that the acoustic difference between Beijing and Taiwan Mandarin is highly significant.

\section{Conclusions}

Tone sandhi is an important phonological phenomenon in Mandarin Chinese and previous studies on Mandarin tone sandhi have focused on Beijing Mandarin. Tone sandhi of other Mandarin dialects has been largely ignored (Yin, 2017). Taiwan has been politically separated from mainland China for 70 years, but there has been no study to compare tone sandhi in Beijing Mandarin with that in Taiwan Mandarin to examine if the two prominent Mandarin dialects display the same or different tone sandhi pattern. Thus, this study investigated range difference in $\mathrm{F}_{0}$ between sandhied tone 3 and lexical tone between Beijing and Taiwan Mandarin. By comparing different Mandarin dialects rather than focusing on one particular dialect of Mandarin Chinese, the present research helped understand and reveal the nature of tonal modifications among dialects of Mandarin Chinese.

For a long time, there has been much debate over whether Mandarin tone 3 sandhi involves a categorical change or tonal reduction; however, the issue has yet to be resolved. The present study aims to shed light on the tone 3 sandhi phenomenon. In the production experiment, samples of range difference between sandhied tone 3 and lexical tone 2 spread in the four different scopes of magnitude of difference across both Beijing and Taiwan Mandarin. The results from this study indicate that tone 3 sandhi among Mandarin dialects is not a homogeneous category, but displays a graded phenomenon of a categorical change and tonal reduction. However, tone 3 sandhi in Beijing and Taiwan Mandarin localizes differently in this continuum of a categorical change and tonal reduction. Tone 3 sandhi in Beijing Mandarin is closer to a categorical change (i.e. changed to lexical tone 2) in this continuum than that in Taiwan Mandarin while tone 3 sandhi in Taiwan Mandarin is closer to a tonal reduction than that in Beijing Mandarin.

Consistent with most of previous acoustic studies on tone sandhi (e.g., Hockett, 1950; Lee-Schoenfeld \& Kandybowicz, 2009; Martin, 1963; Shen, 1990; Xu, 1997; Yuan \& Chen, 2014; Zee, 1980), the results from the present study show that there is acoustic difference in $F_{0}$ between sandhied tone 3 and lexical tone 2 . The acoustic evidence from this study indicates that tone 3 which has undergone the sandhi is not fully neutralized to lexical tone 2, contrary to some of traditional analyses which treat tone 3 sandhi as a categorical change (e.g., Chen, 2000; Duanmu, 2000; Yip, 2002). Degrees in the magnitude of range difference in $\mathrm{F}_{0}$ are varied from dialect to dialect. The experimental results in this study show that range difference in $\mathrm{F}_{0}$ between sandhied tone 3 and lexical tone 2 in Beijing Mandarin is statistically lager than that in Taiwan Mandarin.

The results also suggest that there are gender effects in $\mathrm{F}_{0}$ range difference between sandhied tone 3 and lexical tone 2. Across the two Mandarin dialects, this kind of acoustic difference in female samples is consistently larger than that in male samples. The experimental evidence indicates that tone 3 sandhi occurred in females is more like a tonal reduction phenomenon than that in males.

As a possible further study, more Mandarin dialects such as Northeast, Tianjing and Jinan Mandarin could be investigated to explore the third tone sandhi phenomenon. By examining more Mandarin dialects, a more comprehensive understanding could be gained regarding the nature of tone sandhi among Mandarin dialects.

\section{Acknowledgments}

This research was supported by Research Development Fund from Xi'an Jiaotong-Liverpool Univeristy (RDF-13-02-16).

Thanks are extended for the comments from the participants of 2017 Linguistic Association of Canada the United States Forum.

\section{References}

Boersma, P., \& Weenink, D. (2018). Praat: doing phonetics by computer. Retrieved December 12, 2018, from http://www.fon.hum.uva.nl/praat/

Chao, Y. R. (1930). A system of tone letters. La Maître Phonétique, 45, 24-27.

Chao, Y. R. (1968). A Grammar of Spoken Chinese. Berkeley and Los Angeles: University of California Press.

Chen, M. (2000). Tone Sandhi: Patterns across Chinese dialects. Cambridge: Cambridge University Press. https://doi.org/10.1017/CBO9780511486364

Cheng, C. C. (1973). A Synchronic Phonology of Mandarin Chinese. The Hague: Mouton. https://doi.org/10.1515/9783110866407 
Duanmu, S. (2000). The Phonology of Standard Chinese. Oxford: Oxford University Press.

Hockett, C. F. (1950). Peiping morphophonemics. Language, 26, 63-85. https://doi.org/10.2307/410408

Langacker, R. W. (1987). Foundations of Cognitive Grammar (Vol. 1: Theoretical prerequisites). Stanford: Stanford University Press.

Langacker, R. W. (1991). Foundations of Cognitive Grammar (Vol. 2: Descriptive application). Stanford: Stanford University Press.

Langacker, R. W. (2008). Cognitive grammar: A basic introduction. Oxford, U.K. \& New York: Oxford University Press. https://doi.org/10.1093/oxfordhb/9780199544004.013.0005

Lee-Schoenfeld, V., \& Kandybowicz, J. (2009). Sandhi sans derivation: third tone patterns in Mandarin Chinese. U. Penn Working Papers in Linguistics, 15(1), 125-134.

Lin, H. (2001). A Grammar of Mandarin Chinese. Lincom Europa, Munich, Germany.

Martin, S. E. (1963). Problems of Hierarchy and Interminacy in mandarin Phonology. Bulletin of the Institute of History and Philology, 29, 209-230.

Myers, J., \& Tsay, J. (2003) Investigating the Phonetics of Mandarin Tone Sandhi. Taiwan Journal of Linguistics, $1(1), 29-68$.

Shen, X. S. (1990). Tone coarticulation in Mandarin. Journal of Phonetics, 18, 281-295. https://doi.org/10.1016/S0095-4470(19)30394-8

Shih, C. (1997). Mandarin third tone sandhi and prosodic structure. In J. L. Wang \& N. Smith (Eds.), Studies in Chinese Phonology. Berlin: Mouton de Gruyter.

Wang, J., \& Norval, S. (Eds.). (1997). Studies in Chinese Phonology. Berlin: Mouton de Gruyter.

Wang, W. S.-Y., \& Li, K. P. (1967). Tone 3 in Pekinese. Journal of Speech and Hearing Research, 10, 629-636. https://doi.org/10.1044/jshr.1003.629

Xu, Y. (1997). Contextual tonal variations in Mandarin. Journal of Phonetics, 25, 61-83. https://doi.org/10.1006/jpho.1996.0034

Yin, H. (2003). The blocking of tone sandhi in Mandarin Chinese. In S. Burelle \& S. Somesfalean (Eds.), Proceedings of the 2003 Canadian Linguistic Association Annual Conference (pp. 296-307).

Yin, H. (2017). Comparative study of tone sandhi in Beijing and Taiwan Mandarin. Paper presented at LACUS Forum 44, Hamilton, Canada.

Yip, M. (2002). Tone. Cambridge University Press. https://doi.org/10.1017/CBO9781139164559

Yuan, J., \& Chen, Y. (2014). Third tone sandhi in Standard Chinese: A corpus approach. Journal of Chinese Linguistics, 42(1), 218-236.

Zee, E. (1980). A spectrographic investigation of Mandarin tone sandhi. UCLA Working Paper, 49, 98-116.

\section{Copyrights}

Copyright for this article is retained by the author, with first publication rights granted to the journal.

This is an open-access article distributed under the terms and conditions of the Creative Commons Attribution license (http://creativecommons.org/licenses/by/4.0/). 